\title{
The Transactional Nature of Human Healthcare
}

\section{Lloyd Reeve-Johnson*}

\author{
Institute for Health and Biomedical Innovation, Queensland University of Technology, Australia
}

*Corresponding author: Lloyd Reeve-Johnson, Principal Research Fellow, Translational Research Institute, Institute for Health and Biomedical Innovation, Queensland University of Technology, Brisbane, Australia, E-mail: Iloyd@goydpark.com

\begin{abstract}
Summary
The quality of healthcare, drug innovation, treatment decisions and even approval of drugs are all transaction dependent. Each decision after we seek medical attention is part of a predictable sequence, the totality of which describes the healthcare system. The interplay between the patient, clinician, pharmaceutical company, government or medical insurances paying bills, and, regulators controlling access to the healthcare market is therefore predictable and open to influence. Each of participants in healthcare differs in the way it attempts to maximize its own utility from healthcare: the only commonality is cost.
\end{abstract}

\section{Keywords}

Translational research, Healthcare provision, One health, Healthcare economics

\section{Methods}

Interviews have been conducted over the past fifteen years with pharmaceutical professionals in Europe, USA, Asia, Africa and Australia. Considerable time has been spent over the past three years in major human teaching hospitals, university medical faculties and medical practices analyzing the interactions from the time the patient seeks treatment to the time it is dispensed and the factors which influence this. The system of healthcare delivery has been broken into its component parts and modeled to better understand their transactional nature, similarities and differences and opportunities. This paper represents a synthesis of findings with an analysis of the interplay between the participants in healthcare and the way decisions are influenced during the course of daily healthcare provision.

\section{Results}

It was found that there are six main types of participant in any healthcare process and each of these perceives the value of healthcare differently.

Patients primarily value the effectiveness of treatment by the extent of alleviation of a medical condition, but at the same time have to have the cost of treatment covered by their ability to afford it, or access to public or private health insurance or charitable contribution. The extent that the cost of treatment influences decisions about the patient varies with the economic environment within which the patient exists. i. Payers are primarily concerned with controlling the costs of providing treatment (e.g. Department of Health and Social Security, insurance company, Health Management Organizations etc).

ii. Influencers tend to value effectiveness above cost and have a strong influence often via prescriptive control over the choice of treatment (e.g. general practitioner, nurse, dentist).

iii. Innovators consider the ultimate determinant of value to be the return on the time and money invested (e.g. the pharmaceutical industry, researcher).

iv. The regulator (government agency) places a broader societal value on the cost of treatment, and is primarily charged with protecting the safety of society and the patient population (e.g. national registration authority).

V. Dispenser: Retail pharmacy, wholesaler, mail order, supermarkets, herbalist.

It was found that participants can be grouped into clusters each with sub-levels, all influenced by each other (Figure 1).

It was found that the fundamental activity around which all the participants interact is the decision of a patient to seek treatment for either a real or perceived illness, or to promote health. Without this, nothing else would occur. Even proactive screening depends on the patient once informed, seeking treatment, although this also illustrates the power of information to prompt the sequence leading toward a treatment decision. The process can be broken down into several component parts (Figure 2) and is common to all healthcare provision. However, the way participants interact may differ across markets according to culture, infrastructure and other local factors. There are two supporting decisions. Those decisions regarding cost and those impacting lifestyles which affect compliance with treatment regimens.

It was found that the perception of a health-related 'need' is the starting point in this model. The patient is the primary decision maker at this point, but others in the patient-payer clusters are significant influencers, such as family, friends, and co-workers. The patient perceives a problem exists due to: signs of pain or discomfort; other visual signs; change in function; suggestion, such as through mass media, or increased awareness due to education (from clinician, internet, reading, advertising, etc.). 


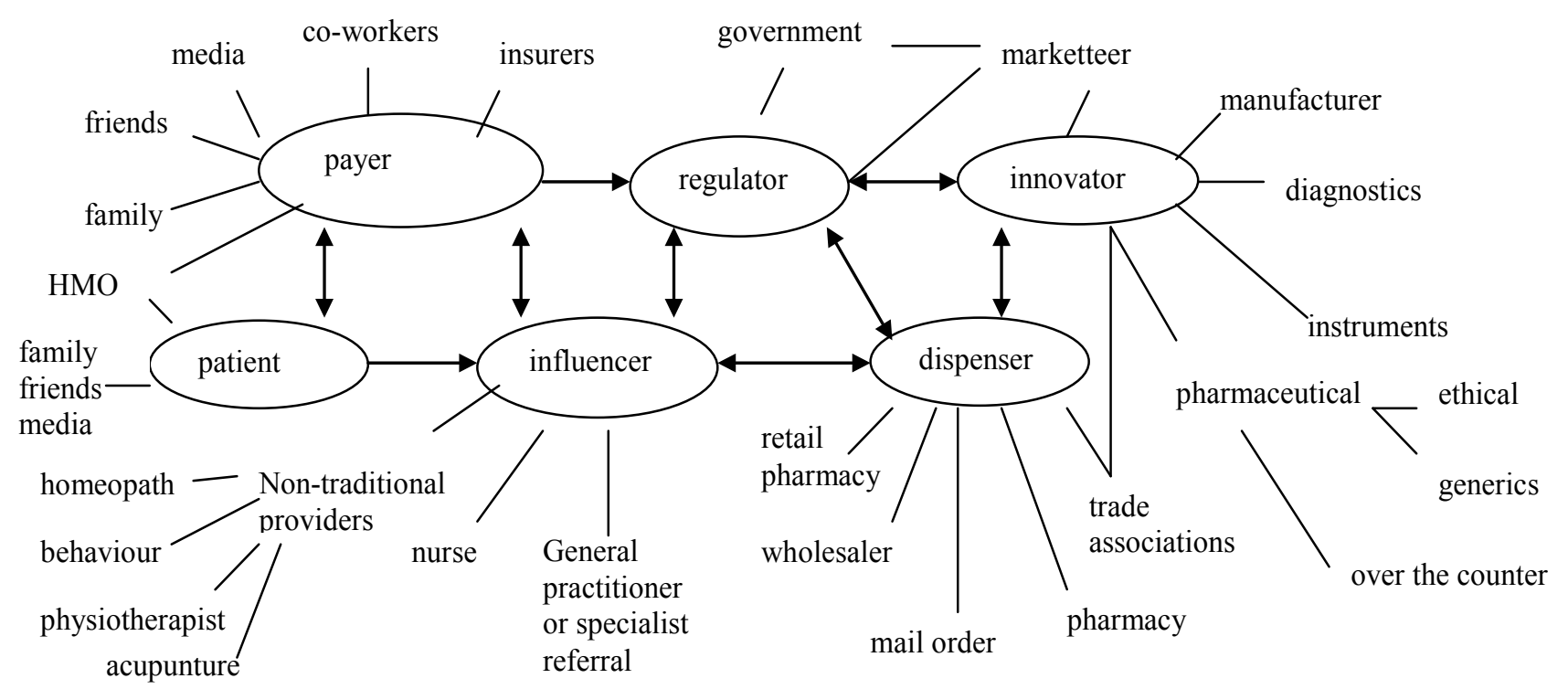

Figure 1: Clusters of influence upon each participant in the healthcare process.

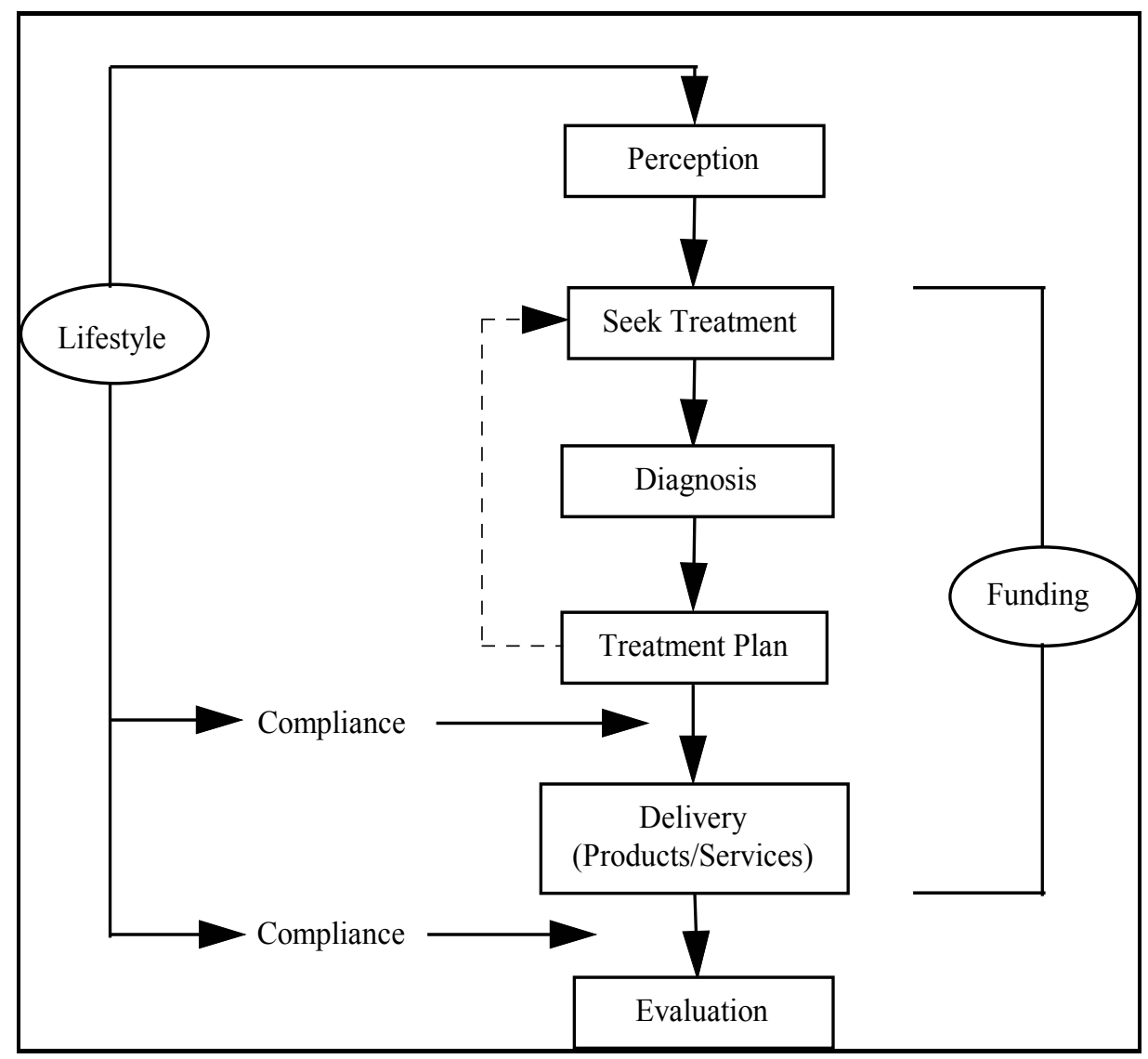

Figure 2: The healthcare process.

Table 1 illustrates four categories which are ranked in order of ease of market penetration for a new pharmaceutical. product.

\section{Explanatory Notes to Table 1}

Category 1 represents a condition that is easily recognized by patient for which it is easy to raise awareness of the disease. An example could be urinary bladder infection (cystitis). For conditions in this category a patient-targeted educational campaign is likely to be successful at developing the commercial market for treatment.

Category 2 represents the situation where it is easy to communicate the importance of the condition to the patient population but patient

Table 1: Two way table illustrating a ease of market penetration when using a targeted innovation strategy based upon perception of illness by the patient.

Ease of raising patient awareness to signs of disease

\begin{tabular}{|c|c|c|}
\hline & High & Low \\
\hline High & 1 & 2 \\
\hline Low & 3 & 4 \\
\hline
\end{tabular}

may not be able to immediately detect the condition. If awareness is raised sufficiently, patients are likely to seek medical attention if they suspect the condition. An example here could be prostatic cancer where 'difficulty urinating' can be easily communicated. Thus 
an information campaign orientated towards both the patient and clinician may be more applicable than solely targeting the general population, because patients with other urinary tract problems which do not require the treatment under consideration will also be presented.

Category 3 represents conditions where it is difficult to effectively communicate the forms that the disease may manifest, such as hormonal (endocrine) problems which can present in many forms. An example might be thyroid problems where over or under activity or changes in sleep patterns and motivation levels may drive a patient to seek medical opinion. In these cases raising clinician awareness and provision of diagnostic backup and screening tests would prove more effective ways of promoting diagnosis and treatment.

Category 4 represents diseases where it is difficult to raise awareness and patients may also not detect signs in the early (more treatable) phases of the disease. An example may be leukaemia where there may not be any early signs evident. Raising clinician awareness through specialist education and introducing pro-active screening to detect onset before evidence of clinical signs may be the only ways of increasing early case presentation in this much more difficult sector.

From the point of view of a targeted innovation strategy, categories 1 and 2 can be influenced much more easily than 3 and 4 , so it is less easy to enter or to expand the market. Category 3 patients are likely to be brought forward at various stages of disease but it would be difficult to target preventive measures at diseases in categories 3 and 4.

It was found that once a patient recognizes a problem, the decision is whether to seek treatment, then where to seek it. The factors influencing the patient to seek treatment include: perceived potential severity of illness-death, disability; cost; accessibility; the belief that something can be done. Once the decision to proceed with medical care has been made, the decision-maker becomes the payer. Where the payer is the patient, the patient can maintain decision making power. The decision at this level is influenced by cost, access and belief that a certain type of provider can help. Where the payer is another body e.g. insurance company, health management organization or government, the decision it influenced by "program rules" which restrict access to some types of providers and restrict the treatment options available to the patient. The patient may decide to become the payer. The payer's decisions are influenced by considerations of their own total cost and perceived treatment quality.

It was found that socio-economic status is relevant (Table 2) when trying to distinguish between high cost, high quality treatment and low cost low quality of treatment. In serious conditions it is likely that the balance of opinion will favor high quality treatment, however in less urgent or less severe conditions, alternatives may be sought (e.g. pharmacy advice or self-medication) and the trade-off may be consciously made to seek a lower cost and lower perceived quality (and possibly effectiveness) of treatment.

It was found that once the presenting complaint of the patient has been evaluated a diagnosis will almost always follow. When the patient has decided to seek treatment within the medical provider network the primary decision maker based upon their expertise becomes a healthcare professional (e.g. a doctor). In markets where patients can readily self-treat, or where a problem is not perceived as severe and where over the counter products are available this role may fill by a pharmacist or para-medical healthcare provider. The factors influencing the medical practitioner's diagnosis are: experience, continuing professional development courses, influence by pharmaceutical manufacturers, professional bodies, payers and the general media. Where the patient has self diagnosed this can be a function of personal experience, education, word of mouth, clusters of influence (Figure 1) and media influence.

It was found that only once the problem has been diagnosed can a meaningful treatment plan is established. The treatment plan, in some cases, creates a loop back to the "seek treatment" decision (Figure 2) such as when the treatment plan of a medical practitioner comprises
Table 2: Two way table illustrating preference of treatment quality based upon the cost of a healthcare visit.

\begin{tabular}{|c|c|c|c|}
\hline \multirow{4}{*}{$\begin{array}{l}\text { Perceived quality of } \\
\text { treatment }\end{array}$} & \multicolumn{3}{|c|}{ Cost of visiting provider } \\
\hline & & High & Low \\
\hline & High & 2 or 3 & 1 \\
\hline & Low & 4 & 2 or 3 \\
\hline
\end{tabular}

Table 3: Two way table illustrating a ease of market penetration (1 = easy, $4=$ very difficult) based upon criteria of treatment cost and efficacy.

\begin{tabular}{|l|l|l|l|}
\hline cost of treatment & \multicolumn{3}{|l|}{ Efficacy of treatment } \\
\hline & High & Low \\
\hline High & 2 & 4 \\
\hline Low & 1 & 3 \\
\hline
\end{tabular}

Table 4: Two way table illustrating a ease of market penetration based upon branding and treatment cost.

\begin{tabular}{|l|l|l|l|l|}
\hline \multirow{2}{*}{$\begin{array}{l}\text { ease of distinguishing product } \\
\text { from rivals }\end{array}$} & \multicolumn{3}{|c|}{ Cost of treatment versus rival product } \\
\cline { 2 - 4 } & \multicolumn{3}{|c|}{ High } & Low \\
\hline & High & 3 & 1 \\
\hline & Low & 4 & 2 \\
\hline
\end{tabular}

Table 5: Two way table illustrating the overriding aim of research and development activities

\begin{tabular}{|c|c|c|c|}
\hline \multirow{4}{*}{$\begin{array}{l}\text { Cost of development (measured in } \\
\text { time and finance required) }\end{array}$} & \multicolumn{3}{|c|}{ Market value } \\
\hline & & High & Low \\
\hline & High & 2 & 4 \\
\hline & Low & 1 & 2 \\
\hline
\end{tabular}

referral to another professional. The treatment plan from medical practitioners can include one or a combination of: pharmaceutical intervention (both prescription and non-prescription); nutritional changes; behavioral modification; surgery, or referral to another provider. These options are not all available to a patient without involvement of a medical practitioner. The patient influences the practitioner by providing information concerning personal wishes or the likelihood of compliance with the treatment plan. The medical provider's treatment plan decision is also cognizant of likely effectiveness, safety and cost. The payer exerts influence on the medical provider and patient through the use of program rules which may restrict the use of certain interventions, or may require specific sequencing of treatment interventions. The payer's program rules are focus on cost, efficacy and safety and typically view costs from a population perspective (as opposed to a case by case). The regulator's decisions are also designed according to the total population, not for an individual. These decisions are a function of the "risk" the regulator is willing to take. The regulator can either take the risk that a valuable, safe treatment is kept off the market, or they can take the risk that an unsafe treatment is placed on the market (i.e. a type 1 or type 2 error).

It was found that when a pharmaceutical product is part of the treatment plan, there are three decisions to be made by the practitioner:

a) Which class of drugs is appropriate for the plan?

b) Which specific molecule is appropriate?

c) Which brand in a generic environment (based on cost/brand recognition)

It was found that the product that the provider will choose is influenced by the effectiveness of the treatment, the cost of the treatment and the ease of distinguishing a product from other products with the same or similar indications of use. Table 3 and table 4 give examples of the ways pharmaceutical innovators are influenced by market conditions to maximize the uptake and profitability of a new product.

Ideal for the patient would be a highly efficacious, low cost treatment (category 1), however, highly efficacious products are generally premium priced (category 2). A high cost, low efficacy product would not be well received by the market, given accurate information. If distinction cannot be made based on cost as in table 3 , 
branding strategy and advertising will play an increasingly important role in distinguishing one product from another (Table 4).

Thus, in order to influence the level of demand for a new product, some basic criteria need to be fulfilled:

1. Easily distinguishable option with few or no rival products and preferential pricing or superior efficacy.

2. Where there are many generic rival products of equivalent efficacy, the product needs to represent an easily discernible option or cost less.

3. Where there is little direct competition, but many alternatives, clear product distinction will have to outweigh relative costs.

4. In a high competition market, with many alternatives and pricing is not favorable, this represents a very difficult market environment in which innovative focus has to be upon production and manufacturing processes to decrease cost of production.

It was found that the patient's decision to comply with a treatment plan is an important determinant of outcome and it is important that the plan is agreed between all involved participants in advance to ensure it is sustainable.

It was found that pharmaceutical innovators target the needs of the patient, medical provider and payer in an attempt to balance the cost of development against the anticipated sales and opportunity cost of other projects not progressed in consequence. Keeping a balanced portfolio is an important part of managing the risk of product development. Where several leads are generated from the same innovation platform and only a couple can be pursued the implication is that the opportunity cost might be as large for the candidate which is not chosen for development as for the lead candidate. Table 5 illustrates the type of prioritization process required when balancing research and development costs against potential market value.

There is a trade off when balancing high cost and high market value against low cost and low market value (both prioritized as category 2). This decision will be partly based upon the cost: benefit ratio of each, the opportunity cost and risk management in terms of probabilized success, portfolio management and overall potential earnings of the project given similar profitability.

It was found that the delivery of a service or a product is instructed in the treatment plan. The delivery of a pharmaceutical product to a patient according to a treatment plan, includes three things: the drug, a delivery mechanism and information about the drug. The primary participant at this stage is the dispenser. The dispenser can be retail dispenser - which includes a stand-alone pharmacy or a pharmacy as part of another retail business (grocery, department store, etc.), a medical practice, a hospital, a specialist practice, or mail order. The influence the dispenser has is a function of which type of dispenser they are and the local regulations governing their activity:

a) Retail dispensers generally have no decision making authority. They can influence the patient when the product is multi-sourced and will inform the patient about cost or plan options when relevant.

b) The medical practitioner as a dispenser has decision making authority over delivery of the drug. This decision making ability may be constrained by the payer through social security or insurance reimbursement rules.

c) Mail order dispensers have influence similar to that of a retail dispenser.

The influence on drug delivery decisions, are primarily a function of the dispenser type's profitability. In other words, if a dispenser has the freedom to influence a patient, how they choose to influence a patient is driven by what is most profitable for the dispenser. The dispenser may also be influenced by concerns for the patients' cost in a competitive market.

The delivery decisions influenced by the dispenser are primarily decided on by the payer and the patient. The regulator has decision making authority over the types of pharmaceutical dispensers that exist in a given market.

It was found that a key determinant of success for a pharmaceutical company is developing an ability to influence each of the decisions in the transaction. Figure 3 is a worked example, where the probability of each set of decision choices has been set at equal (e.g. $50 \%$ chance of choosing to treat versus not treat, or a $33 \%$ chance of choosing between three possible providers of treatment, etc.). The exact trend can be established by local market research and each of these sets of decisions can be adapted according to concurrent trends. Through education or awareness campaigns, it can be made more likely that once' lumps' are detected by a person, treatment will be sought. This decision could realistically be raised to over $90 \%$ seeking treatment versus those choosing to ignore 'lumps'. In the case of treatment for mild urinary tract symptoms, however, education campaigns could also be used to influence people not to initially seek treatment from a medical provider and the option, set arbitrarily at 33\%, may become only $10 \%$. In doing so, self-medication could be increased to account for the majority of treatments, increasing over-the-counter sales and taking the expense of medical consultation out of the system.

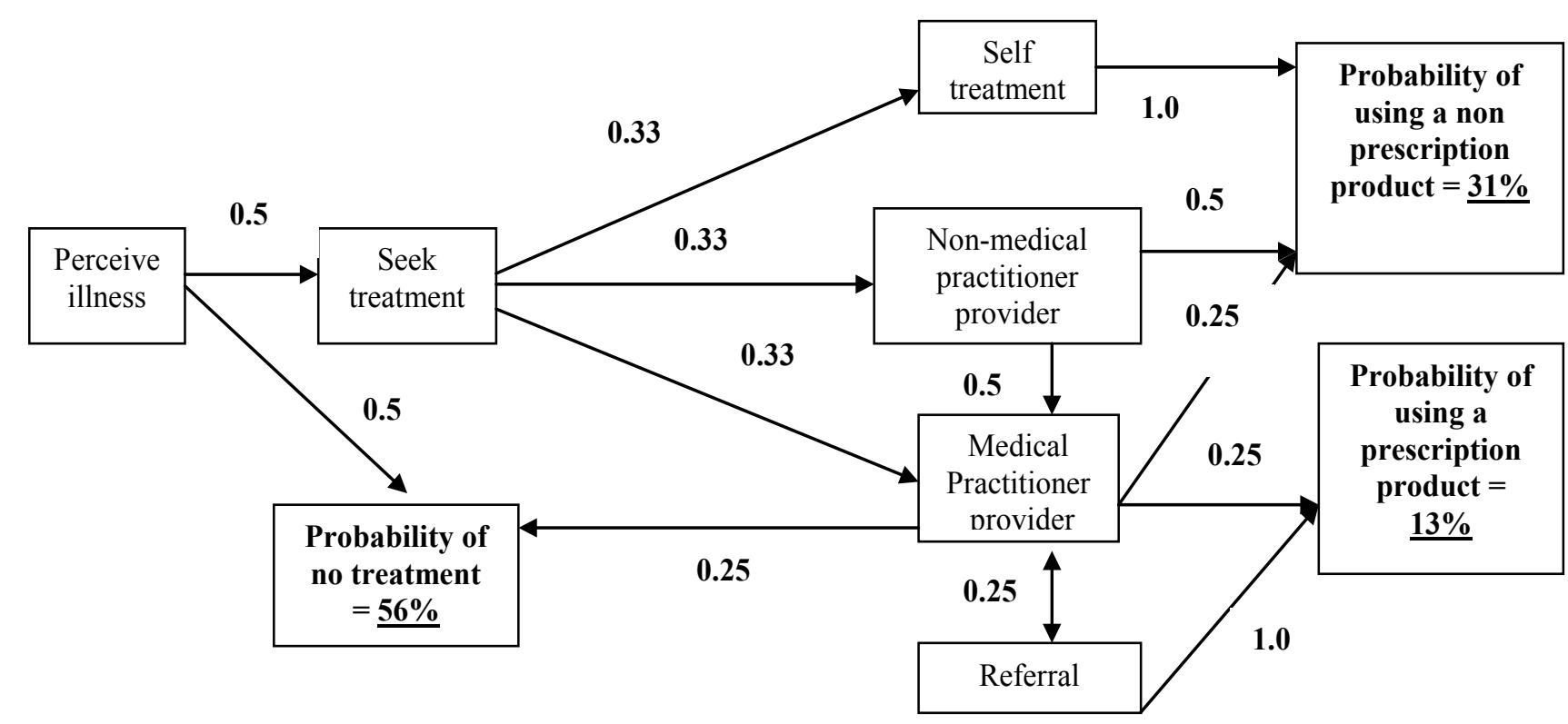

Figure 3: Worked example of a decision cascade from the point of perception of illness through to dispensing of therapy. 
Table 6: Summary of the primary decision makers and influencers at each level of the adoption process.

\begin{tabular}{|c|c|c|c|c|c|c|}
\hline Participant/Stage & Patient & Medical provider & Payer & Dispenser & Regulator & Innovator/Manufacturer \\
\hline Perception & $\begin{array}{l}\text { Primary decision } \\
\text { maker }\end{array}$ & $\begin{array}{l}\text { Influence through } \\
\text { routine screening }\end{array}$ & $\begin{array}{l}\text { Influence through } \\
\text { paying (or not) for } \\
\text { routine screens }\end{array}$ & & & $\begin{array}{l}\text { Influence through } \\
\text { awareness campaigns }\end{array}$ \\
\hline Seek treatment & $\begin{array}{l}\text { Primary decision } \\
\text { maker }\end{array}$ & $\begin{array}{l}\text { Influence through } \\
\text { availability and cost }\end{array}$ & & & $\begin{array}{l}\text { Influence access and } \\
\text { availability }\end{array}$ & $\begin{array}{l}\text { Influence through help } \\
\text { lines and educative } \\
\text { campaigns }\end{array}$ \\
\hline Diagnosis & $\begin{array}{l}\text { If treat, then decision } \\
\text { maker }\end{array}$ & $\begin{array}{l}\text { Primary decision } \\
\text { Maker }\end{array}$ & & $\begin{array}{l}\text { Influence in } \\
\text { self-treatment } \\
\text { situation }\end{array}$ & & $\begin{array}{l}\text { Influence by education, } \\
\text { provision of diagnostics }\end{array}$ \\
\hline Treatment plan & $\begin{array}{l}\text { Influence through } \\
\text { opinion and requests }\end{array}$ & $\begin{array}{l}\text { Primary decision } \\
\text { Maker }\end{array}$ & $\begin{array}{l}\text { Secondary } \\
\text { decision maker, } \\
\text { influences through } \\
\text { reimbursement rules }\end{array}$ & $\begin{array}{l}\text { Primary/ } \\
\text { Secondary } \\
\text { decision maker } \\
\text { in self-treatment } \\
\text { situation }\end{array}$ & $\begin{array}{l}\text { Tertiary decision } \\
\text { maker, controls band } \\
\text { of possible treatments }\end{array}$ & $\begin{array}{l}\text { Influence primary decision } \\
\text { maker regarding selection } \\
\text { of product and its inclusion } \\
\text { in treatment plan }\end{array}$ \\
\hline Delivery & & & & $\begin{array}{l}\text { Primary decision } \\
\text { maker. Some } \\
\text { delivery decisions }\end{array}$ & $\begin{array}{l}\text { Influence type of } \\
\text { dispensers \& level of } \\
\text { control }\end{array}$ & \\
\hline Evaluation & $\begin{array}{l}\text { Primary decision } \\
\text { maker }\end{array}$ & $\begin{array}{l}\text { Secondary decision } \\
\text { maker - if patient } \\
\text { returns for evaluation }\end{array}$ & & & & $\begin{array}{l}\text { Influence through } \\
\text { help lines and making } \\
\text { comparative data available }\end{array}$ \\
\hline Compliance & $\begin{array}{l}\text { Primary decision } \\
\text { maker }\end{array}$ & Limited control & $\begin{array}{l}\text { Influence through } \\
\text { ease of payment and } \\
\text { level of cover }\end{array}$ & & & $\begin{array}{l}\text { Influence through } \\
\text { education and help lines }\end{array}$ \\
\hline
\end{tabular}

The types of product most likely to be adopted can therefore be influenced. Using this type of model a pharmaceutical company can rationalize the decision steps by cost effectiveness to target resources to maximum effect.

During a treatment plan and after completion, there must be evaluation of the plan's effectiveness in solving the problem identified during diagnosis. The patient is the primary decision maker with regard to whether or not a treatment plan has worked and evaluates efficacy in relation to total cost of treatment plan. Patient evaluations are based on: symptomatic relief, ability to resume normal activities or demonstrable change in the condition (e.g. tumor shrinkage). The clinician co-evaluates a treatment plan based on their visual evaluation, the patient's own evaluation, repeat investigations and empirically upon whether any better outcome could be hoped for using existing alternative treatments. The clinician only has the potential to evaluate a plan if the patient returns to the provider after the treatment plan was implemented. So, in many cases the clinician must assume a result

\section{Discussion}

The patient has a great deal of influence over the entire process and typically controls whether or not a healthcare transaction proceeds at all. If the patient does not perceive a problem exists, nothing happens. But just because an illness exists and is recognized, it does not mean treatment will be sought. Lack of awareness of solutions, denial and fear of the consequences are all relevant factors [1-3]. The more difficult a problem is to perceive, the less likely treatment will be sought. When it comes to deciding where to seek treatment, the patient has a variety of choices and can choose to stop and exit the transaction any time. Medical practitioners in general practice are important influencers with substantial numbers of patients waiting to receive treatment, however, having sufficient time to explain the disease, to share the options for treatment and internalize the decision into a collaborative disease management effort in which the patient is fully engaged and therefore more likely to comply with the regimen is important. It is helpful at this time to discuss the realistic expectation for benefits and side-effects as well as the consequences of not completing treatment. By virtue of improving compliance with the treatment protocol, the patient is more likely to benefit to the full extent from the treatment and the pharmaceutical company will receive the full revenue.
Pharmaceutical companies are fully aware of the transactional nature of healthcare, yet many other participants in the system may not perceive the economic fundamentals as clearly. The patient has a very large amount of influence over the transaction as a whole. If a problem is not perceived, or treatment is not sought, then no sale will occur and innovation will not be utilized. The patient's decision making capability or influence is constrained by clinicians and payers, but in different ways for different reasons. The clinician's influence over the patient is primarily due to either their expertise or through access to products limited by prescription. The patient believes he is not qualified to identify and solve certain medical problems, and so gives control of this decision to the expert. The clinician tends to be the decision maker at the diagnosis stage and to be the primary decision maker at the treatment plan stage but is constrained by the payer. Clinicians can influence patient selection at the perception or seek treatment stage through screening (e.g. routine blood profiling). It is likely that the level of information provided on the treatment options has a large effect at this stage. Table 6 summarizes the key decision makers at each level of the healthcare transaction and who influence the progression though a series of decision which are common to most modalities of healthcare.

The patient allows the payer to exert influence for economic reasons and cedes a degree of control to the payer in return for the payer's role in bearing some of the patient's costs.

The payer, however, does not make decisions on a real time basis, like the patient and provider. The payer acts on the decision in advance, through a set of program rules.

\section{Conclusions}

- Provision of healthcare is fundamentally a transaction and is the mechanism by which all of the participants in healthcare interact and rationalize their perspectives of value into a common economic exchange.

- Patients and healthcare professionals may be less aware of the underlying economic imperatives and ways that they may be influenced than pharmaceutical companies, dispensers, insurance and government funders who have clear economic motives.

- In the healthcare industry demand generally pre-exists and education, awareness and supply of treatments influence the uptake of new products. 
Central to the aggregate transaction is the individual adoption process of the patient, which includes the perception of illness, the decision to treat, diagnosis, setting up the treatment plan, the delivery of the drug and evaluation of the effectiveness of the treatment plan which impacts compliance. Each of these steps is a potential point of influence and can be used to influence the adoption of products. These can be used to target market niches to maximize rapid adoption of new products.

\section{References}

1. Reeve-Johnson $L$ (2003) Quantifying and maximizing the value of innovation in the pharmaceutical industry. J.vet.Pharmacol.Therap 26: 19-55.

2. Reeve-Johnson $L$ (2016) Chapter in Practical Veterinary Forensics ed Bailey D. Macro-economic incentives for Translational research and One Health collaborations. CABI publishing, Cambridge.

3. Reeve-Johnson $L$ (2015) Translational Research: putting the right price on innovation. Vet Record 173: 312-313. 